\title{
Role of Cemented Bipolar Hemiarthroplasty for Comminuted Inter-trochanteric Femur Fracture in elderly osteoporotic patients through a modified Transtrochanteric approach- "SION Hospital Modification".
}

\author{
Dr Atul Patil ${ }^{1}(\mathrm{MS}, \mathrm{DNB})$, Dr Muqtadeer Ansari ${ }^{1}(\mathrm{MS}, \mathrm{DNB})$, Dr Aditya \\ Pathak $^{2}$ (MS,DNB), Dr A B Goregaonkar ${ }^{3}(\mathrm{MS})$, Dr C J Thakker (MS,DNB). \\ 1.Assistant Professor, ( Primary authors and surgeons) Department of Orthopaedics, Lokmanya tilak Medical \\ College and Hospital, Sion, Mumbai, India 400022. \\ 2.Assistant Professor, (Corresponding Author and surgeon) Department of Orthopaedics, Dr R N Cooper \\ Hospital, Vile parle, Mumbai, India 400056 \\ Ex Registrar - Department of Orthopaedics, Lokmanya tilak Medical College and Hospital, Sion, Mumbai, \\ India 400022. \\ 3.Professor and Head of Department of Orthopaedics, Department of Orthopaedics, Lokmanya tilak Medical \\ College and Hospital, Sion, Mumbai, India 400022. \\ 4.Ex-Professor and Head of Unit, Department of Orthopaedics, Lokmanya tilak Medical College and Hospital, \\ Sion, Mumbai, India 400022.
}

\begin{abstract}
We operated 126 elderly osteoporotic patients with mean age of 65.5 years who sustained Comminuted Inter-trochanteric femur fracture treated with Cemented Bipolar hemiarthroplasty and Tension band wiring for Greater trochanter through transtrochanteric approach. Mean Harris hip score at the mean follow up of 2.92 years was 80.76 and showed a statistically significant improvement as compared to preoperative scores. Mean blood loss during the mean operative time of $61.35 \mathrm{~min}$ was $321 \mathrm{ml}$.

In our case series we came across some serious complications like infection, dislocation, osteolysis, Non-union Greater trochanter, protusio and implant breakage but no fatalities were reported. 5 of our patient underwent repeat surgery in form of Total Hip Replacement and 1 Excision Arthroplasty. From our study we would like to suggest that Cemented Bipolar hemiarthroplasty is a viable technique for elderly osteoporotic patients with Comminuted inter-trochanteric femur fracture using "modified Sion hospital" technique with no trauma to abductors or external rotators of hip and sciatic nerve as we approach the hip through the fracture site itself and not posteriorly as in Southern Moore's approach. It also helps in faster rehabilitation and recovery in elderly osteoporotic patients. Modified "SION HOSPITAL" technique needs further evaluation and level $1 \& 2$ study for its efficiency comparing it to other approaches and its usage for Total hip arthroplasty in comminuted inter-trochanteric fractures.
\end{abstract}

Keywords: Inter-trochanteric fractures, comminuted, unstable, Elderly osteoporotic, cemented Bipolar, Hemiarthroplasty.

\section{Introduction.}

Comminuted, unstable inter-trochanteric femur fractures are one of the most common fractures in elderly osteoporotic patients. Both Extracapsular and intracapsular neck femur fractures constitute one of the major cause of mortality in elderly population ${ }^{1}$. The mortality rates after occurrence of these fractures is as high as 20 percent in the first post-operative year ${ }^{2}$. These fractures are caused generally by trivial trauma like fall in bathroom or on floor, slipping while walking etc. Stable Inter-trochanteric fractures have been treated successfully with open reduction and internal fixation using Dynamic hip screw, Cephalomedullary nail or Jewett blade plate etc. But it has been a challenge, treating unstable comminuted inter-trochanteric femur fractures ( Evan type III and IV, AO/OTA type 31- A2.2 and 2.3) as in elderly osteoporotic patients, anatomical reduction and early rehabilitation both are essential ${ }^{3,4}$.Cut-out, Excessive head collapse, Plate breakage, plate pullout, Z-effect, reverse Z effects are few of the implant related complications especially with unstable type of fractures ${ }^{5,6}$.Intramedullary device has shown better results with less cut-out rates in osteoporotic comminuted inter-trochanteric femur fractures but on the other hand Endoprosthetic replacements have proved good midlong term survivorship and early rehabilitation ${ }^{7,8,9}$. The main motive of performing surgery in a comminuted inter-trochanteric fracture femur was early ambulation and avoids complications associated with Open reduction and internal fixation in elderly osteoporotic patients ${ }^{10}$. This aim is fulfilled to some extent by Bipolar hemiarthroplasty. 
The treatment of osteoporotic unstable comminuted inter-trochanteric femur fracture in elderly patients has still been a controversial debate. The aim of our study was to evaluate the efficiency of Bipolar hemiarthroplasty in such cases in terms of mid-term survivorship and functional outcome.

\section{Material and Methods}

126 patients underwent Cemented Bipolar hemiarthroplasty between 2007 and 2012 who had sustained inter-trochanteric fractures. All patients were operated by primary and corresponding authors by Transtrochanteric approach. We selected this approach as in all our cases greater trochanter and lateral wall was fractured so in all cases femoral head was approached through the fracture site. We had kept certain inclusion criteria for our study.

Inclusion Criteria -

1) Age- More than 55 years.

2) All Patients were osteoporotic, as confirmed on Bone mineral Density as per WHO guidelines. ${ }^{11}$

3) All sustained Evans type III and IV, AO/OTA type 31- A2.2 and 2.3 of Inter-trochanteric Fractures. Unstable, Comminuted Fractures only.

4) No other fracture sustained only isolated Inter-trochanteric fracture

5) No head injury or other injury.

6) Fracture less than 3 weeks old

\section{Exclusion Criteria-}

1) Patients not willing to participate in the study.

2) Any Transcervical,subcapital, basicervical or subtrochanteric fractures.

3) Non comminuted IT fractures.

\section{Anaesthesia -}

Almost all the patients in our study were given Hypotensive epidural anaesthesia, Barring few who were give general anesthesia.

\section{Operative Technique -}

With patient in lateral position, incision was taken on lateral aspect of hip, centered on proximal aspect of greater trochanter .Proximally incision was curved posteriorly towards Posterior superior iliac spine. Tensor Fascia Lata was cut in the direction of skin incision. Proximally fibres of gluteus maximus were dissected along skin incision to expose fracture site. Now we carefully dissected fracture site and retracted fracture fragments of greater trochanter, so as to reach base of femur neck. We extracted femur head and the attached neck through this "trans troachanteric window'. After extraction of femoral neck and head, acetabulum was inspected and cleared of any of remaining bone pieces. Then we started femoral canal preparation using reamer and serial broach's. After preparing femoral canal we drilled two holes on lateral aspect of proximal femur $5 \mathrm{~cm}$ below vastus ridge. 2 Holes were placed $2 \mathrm{~cm}$ away from each other. A stainless steel wire was passed from outside through one hole in the medullary canal and then taken out from another hole. Now the two free ends of the wire are lying on lateral aspect of femur. The implant placement is now started with special emphasis on-

1. Ante version which is decided by using long axis of the leg as guide.

2. Length of the implant to be inserted in the femur is decided by carefully judging soft tissue tension. Also tension is checked with Help Of Shuck Test showing less than 2-3mm of displacement, no dislocation of the trial implant with , 10 degree of extension, 50 degree of abduction, 40 degree of adduction external rotation of 30 degrees and flexion $90-100$ degrees and internal rotation of 40-50 degrees. Also Limb length was aimed to maintained almost same as that of other limb and the amount of stem to be sinked in was carefully observed and marked both on trial and final implant before cementing and then cementing was done.

3. No excess cement should spread on fracture site as it interferes with union of the fracture.

We had reconstructed all the calcar with help of cement. Once the Final implant of adequate size is inserted, the hip is reduced. The fracture pieces of GT are now approximated to each other. A wire passer is passed above tip of the trochanter deep inside the abductors. Previously passed wire is now crossed over and passed through the wire passer, so as to complete figure of 8 which is now tightened. This achieves compression across the fracture site and restores the abductor mechanism of hip. Closure is done in layers carefully over a negative suction drain.

\section{Post-operative and Rehabilitation Protocol-}

All patients were kept under analgesic effect with help of epidural catheter till two days post-operative. All the patients operated, except for those who had landed with few immediate complications were started with 
Physiotherapy . All patients were treated with Quadriceps strengthening exercises immediately post op and full weight bearing walk next day with help of walker for first 6 weeks post-operative. Thereafter patients started full weight bearing with support of a stick. Patients were instructed to use only Western style commode for Toilet activity, strictly avoid Indian style commode, avoid activities involving squatting and cross legged sitting for the rest of their life as a precautionary measure to avoid dislocation of the bipolar hemiarhoplasty. Patients were followed up regularly at 2 weeks, 4 weeks, 3 months post-operatively and then yearly once.

\section{Results}

Statistical Analysis was done by the statistician on Windows XP, Using Microsoft word, Microsoft excel and SPSS 13 by statistician.

Patients were evaluated serially pre-operatively, 3 months post-operatively and then at final follow up using Harris Hip score.

Variables-

We had 126 patients included in our study with 64 female and 62 male patients. $57.9 \%$ patients had suffered the injury due to trivial trauma like fall from chair/bed, slip in bathroom or in house on floor. Rest $42.1 \%$ of patients had suffered from major trauma like fall from significant height, road traffic accident or fall from stairs. The data regarding all the variables are as given in Table 1.

Table No. 1 :

Statistics of various variables among the 126

cases

\begin{tabular}{|c|c|c|c|c|c|c|c|}
\hline \multirow[b]{2}{*}{ Variables } & \multirow[b]{2}{*}{ No. } & \multicolumn{4}{|c|}{ All cases } & \multirow{2}{*}{$\begin{array}{l}\text { Minimu } \\
\text { m }\end{array}$} & \multirow{2}{*}{$\begin{array}{l}\text { Maximu } \\
\text { m }\end{array}$} \\
\hline & & Mean & SD & $\begin{array}{l}\text { Media } \\
\text { n }\end{array}$ & IQR & & \\
\hline Age (years) & 126 & 65.75 & 7.85 & 66.00 & 12.00 & 55.00 & 88.00 \\
\hline Harris hip score:Pre-op & 126 & 12.49 & 3.78 & 10.00 & 5.00 & 8.00 & 20.00 \\
\hline Harris hip Score:3 months post-op & 126 & 69.60 & 5.92 & 70.00 & 6.00 & 40.00 & 78.00 \\
\hline Harris hip score:Final follow up & 126 & 80.76 & 4.70 & 80.00 & 4.00 & 60.00 & 88.00 \\
\hline Follow-up (years) & 126 & 2.92 & 1.30 & 2.50 & 2.00 & 1.00 & 6.00 \\
\hline Blood Loss (ml) & 126 & $\begin{array}{l}321.0 \\
3\end{array}$ & $\begin{array}{l}122.2 \\
1\end{array}$ & 300.00 & 100.00 & 200.00 & 800.00 \\
\hline Operative time (min) & 126 & 61.35 & 15.72 & 60.00 & 20.00 & 40.00 & 100.00 \\
\hline Time between injury \& operation (days) & 126 & 3.56 & 2.65 & 3.00 & 2.00 & 1.00 & 13.00 \\
\hline Stay in Hospital post-op(days) & 126 & 4.83 & 1.22 & 5.00 & 2.00 & 3.00 & 7.00 \\
\hline
\end{tabular}

Note: IQR= Interquartile Range (i.e. 75th Percentile-25th Percentile)

Above Table shows that we had total of 126 patients with mean age of 65 years and mean follow up of 2.9 years. Our mean operative time was 61.35 minutes with mean blood loss of $321 \mathrm{ml}$. We had operated all the patients within first two weeks of trauma with mean time between injury and operation being 3.5 days. The biggest advantage with this surgery was that all the patients were mobilized immediately on next day of surgery so the recovery and rehabilitation was quick with mean post-operative stay in hospital being 4.83 days. Mean Harris hip score at 3 months follow up and final follow -up showed significant improvement from pre-op mean of 12.49 to that of 69.60 and 80.76 respectively .This improvement was statistically significant. Of 126 patients we had $76.2 \%$ patients with good Harris hip score, $21.4 \%$ patients had fair and $2.4 \%$ patients had poor scores .Harris Hip score had no statistical significance or association with any of the variables used in our study.

\section{Complications-}

In our study we had certain significant complication but no mortalities. We divided the complication into immediate(within 3 months post-operative) and delayed. We had 11 patients with immediate complication and 8 with delayed complication. Details of the same are shown in table 2.

Table 2- Complications -

\begin{tabular}{|l|l|l|l|}
\hline Complications & Immediate & Delayed & Measures Taken \\
\hline Dislocation & 1 & & $\begin{array}{l}\text { Closed Relocated under } \\
\text { Anesthesia }\end{array}$ \\
\hline $\begin{array}{l}\text { Implant } \\
\text { Loosening/osteolysis }\end{array}$ & 1 & 2 & $\begin{array}{l}\text { Both were converted to Total } \\
\text { hip arthoplasty }\end{array}$ \\
\hline Infection & 1 Immediated infection - \\
debridement and antibiotics
\end{tabular}




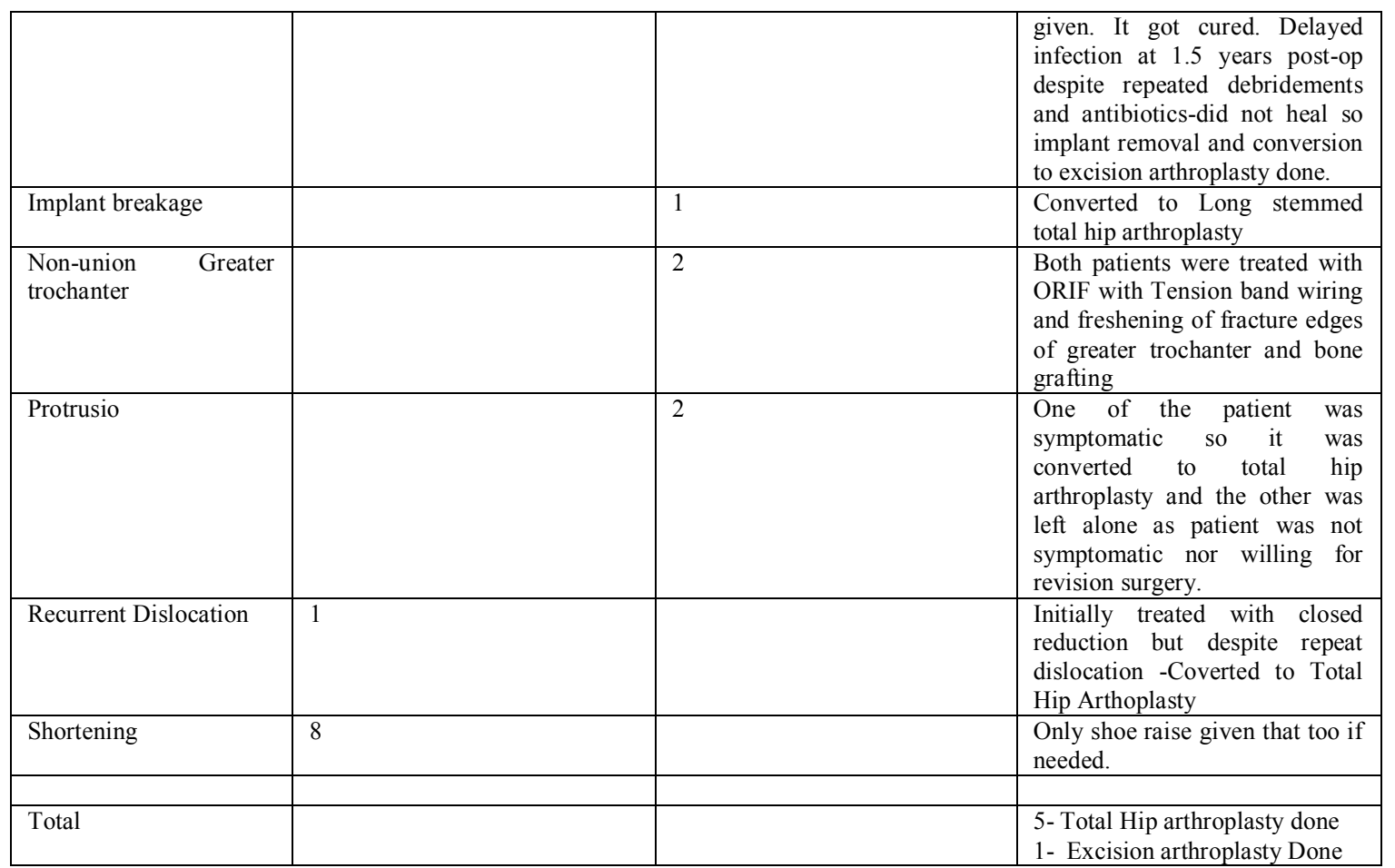

2 patients encountered with protrusion were at 4.5 years and 5.5 years of Follow-up. 2 patients encountered with anterior thigh pain and osteolysis were at the mean age of 3 and 4.5 years. One patient at follow-up of 2 years had history of trivial trauma with implant breakage. The cause of loosening could not be ascertained and was considered to be aseptic . Non of the complication was directly attributable to surgery statistically. But the Harris hip score was found to have statistical significance in patients with complications with poor scores.

\section{Discussion.}

It is beyond doubt that implants like Dynamic hip screw, gamma nail and other intra-medullary devices are the mainstay of treatment of Inter-trochanteric fractures ${ }^{12,13}$. But complications like screw cut-out, Plate breakage, Z-effect, Reverse Z-effect are some of the implant related complication encountered in unstable comminuted inter-trochanteric femur fractures , mainly in osteoporotic and elderly patients. ${ }^{5,6}$ Maintenance of fracture reduction which should be anatomical or near anatomical, proper positioning of the implant and monitored weight bearing are the pre-requisites to achieve good functional outcomes. But In osteoporotic elderly patients with Inter-trochanteric comminuted fracture femur the bone quality is poor, cut-out rates of implant is high, loss of reduction is an known fact which leads to poor functional results. Also Ambulation is prevented in elderly patients with fear of such complications, which in elderly patients causes other complications like Aspiration Pnuemonitis, Bed sores, Deep vein thrombosis,atelectasis etc which gets further complicated with existing co-morbidities. ${ }^{14}$ Hip fractures hence are most serious health care problems affecting elderly patients. There were an estimated 1.66 million hip fractures world-wide in 1990, this worldwide annual number will rise to 6.26 million by the year $2050^{15,16}$. Failure rates between $6 \%-32 \%$ have been reported for internal fixation of both stable and unstable intertrochanteric hip ${ }^{17,18}$.In our series we had very few implant related complication. Also we had no patients with complications like Bed sore, aspiration pnuemonitis or atelecasis as all the patients were immediately mobilized on next day of operation. Even care was taken that those patients with immediate or delayed complication were given priority and needful was done to see to it that in them early mobilization was started.

Several studies in literature have shown that results with Cemented bipolar hemiarthroplasty are good. It helps in early mobilization of patient with good and fast improvement in Harris Hip score. Complications like pressure sores, aspiration, Pneumonitis are very rare with this surgery. Cemented bipolar hemiarthroplasty has given constant good results in terms of early ambulation and good mid-term survival rates in comminuted unstable inter-trochanteric fractures and results are constant as compared to variable results given by osteosynthesis ${ }^{19,20,21}$.Even our results were synchronous to the above studies in terms of early mobilization, less implant related complications and faster over-all rehabilitation.

There have been many case series and comparative studies which have compared results of osteosynthesis and cemented bipolar hemiathroplasty for similar unstable inter-trochanteric fractures. They have proved that final outcome in both the groups were more or less comparable except for the fact that there was 
early ambulation in hemiarthroplasty group. They have also stated that blood loss and need for transfusion was more in hemiarthroplasty group as compared to osteosynthesis ${ }^{22,23}$. We do agree that Blood loss and need for blood transfusion is more in this surgery. We had mean blood loss of $321 \mathrm{ml}$ with minimum of $200 \mathrm{ml}$ and maximum of $800 \mathrm{ml}$.

The rate of repeat operation in case series with osteosynthesis in elderly patients has been reported to be as high as $8-16 \%$. Repeat surgeries in elderly patients with other co-morbidities have shown more medical complications and implant related complications ${ }^{24,25}$. Our series had revision surgery $4.8 \%$ which is less than the osteosynthesis group.

We had used standard Tension band wiring technique for fixation of greater trochanter as shown in case series by Zhang $Q$ et $\mathrm{at}^{26}$. In our series we had encountered two delayed non - union of greater trochanter which were treated with repeat open reduction and fixation with circlage wire and bone grafting. Both patients presented clinically with pain at greater trochanter and decrease active abduction at follow-up of 4-5 months post-operatively.

Haentjens et $\mathrm{al}^{27}$ and Geiger et $\mathrm{al}^{28}$ in their case series showed dislocation rate in the patient group who underwent total hip arthroplasty was significantly higher (12\% to $44.5 \%)$ than those who had bipolar arthroplasty(0 to $3.3 \%)$. We too had two $(1.5 \%)$ patients who had got dislocated post-operatively. One of them were treated with closed relocation under anaesthesia and the other had to be treated with Revision surgery in form of total hip arthroplasty.

Study by George $\mathrm{J}$ et al ${ }^{29}$ has shown Ten-year survivorship of cemented bipolar hemiarthroplasty in inter-trochanteric fracture femur free of reoperation for any reason was 93.6\%. We in our series have shown a good early to mid-term survivorship at our mean follow up of 2.9 years with minimum of 1 year and maximum of 6 years.

The literature supports that all three approaches have comparable dislocation rates when using the posterior approach augmented with soft tissue repair and it is apparent an adequate soft tissue repair when performing the posterior approach greatly reduces the relative risk of dislocation. But certain studies have also shown that there are higher rates of dislocation with posterior approach when compared with transtrochanteric and antero-lateral approach. Studies have also shown that former has less rate of ectopic ossification as compared to the latter two. Also there is higher rate of non-union with trans-trochanteric approach thus affecting the abductor lever arm and can lead to Lurching gait ${ }^{30}$.We in our case series had implemented a novel Transtrochanteric approach. We had selected all patients with comminuted inter-trochanteric fracture femur which has Greater trochanter as a separate fragment. We had to repair Greater trochanter with tension band wiring irrespective of the approach used. So we did not use Southern Moore's approach. As the greater trochanter fragment was elevated supero-posteriorly we saw the fracture neck and the head through the fracture site. So there was no need to cut external rotators which causes bleeding, nor we had to split Gluteus maximum or any of the abductors. Since we were constantly on lateral aspect nerve was always safe posteriorly. Above mentioned were the advantages of this approach in Comminuted inter-trochanteric fractures. We would like to name this approach "SION HOSPITAL" modification of Transtrochanteric approach for Comminuted inter-trochanteric fractures. There were two cases of dislocation and two cases of non-union Greater trochanter. We postulated that dislocation may be most probably due to inadequate version and possible non union due to either cementing technique or inadequate fixation. But the exact cause could not be ascertained.

In the short term, unipolar or bipolar hemiarthroplasty seem to give better results than open reduction and internal fixation in the treatment of unstable intertrochanteric hip fractures in terms of mortality and morbidity rates, complications, early rehabilitation and returning to daily living activities. Long-term problems such as loosening, protrusio, stem failure, late infections and late dislocations have been prevalent. Because life expectancy increases in all countries, long-term disadvantages of the hemiarthroplasty may outweigh its shortterm advantages. ${ }^{31,32}$ Our series too have shown such complications and long term survivorship of this implant would always be questionable despite its advantages.

Our results were comparable to study by Sancheti et al ${ }^{33}$ and Elmorsy et al ${ }^{34}$ which has shown that primary bipolar hemiarthroplasty in comminuted extra-capsular neck femur fracture five early mobilization, stable and painfree hip with early rehabilitation and return to daily routine life with less re-operation rate and is fairly economical especially for developing countries.

Our study is an Level 4 study, hence firm conclusions cannot be as ascertained .Finally we agree with The Cochrane Database analysis has also quoted insufficient evidence to prove superiority of osteosynthesis or primary arthroplasty in inter-trochanteric fractures ${ }^{35}$.So for the same a very well co-ordinated multicentric randomized double blinded trial is essential to prove efficacy, feasibility and long term survivorship. Also the use of this "SION HOSPITAL" Modification of transtrochanteric approach in comminuted inter-trochanteric fracture both for total hip arthroplasty and hemiarthroplasty is yet to be established. Its comparative study with other approaches too needs further evaluation. 


\section{Conclusion.}

Although Bipolar Hemiarthoplasty has its set of long term complications questioning its long term survivorship, but it is an excellent and viable option for early ambulation and good early-mid term survivorship , with less implant related complication for elderly osteoporotic patients with comminuted inter-trochanteric fracture femur. Also 'SION HOSPITAL' modification of transtrochanteric approach needs further extensive study for its efficiency with respect to total hip arthroplasty and Level I/II studies comparing with other approaches. In our study this approach is a good technique without harming Sciatic nerve, External rotators of and abductors of hip.This is used for endoprosthetic replacement in comminuted inter-trochanteric fractures with Greater trochanter as separated fragment.

\section{Aknowledgement - None}

\section{Figure Legends -}

Figure 1-

A-Pre-operative pelvis with both hips antero-posterior view with comminuted unstable intertrochanteric fracture

B- Pre-operative lateral view showing comminuted unstable intertrochanteric fracture .

C- Immediate Post-opeartive view showing cemented bipolar hemiarthroplasty with tension band wiring for Greater trochanter.

D- X-ray showing pelvis with both hips and antero-posterior view with cemented bipolar hemiarthroplasty with tension band wiring for Greater trochanter at 5 years post-op.

E- X-ray showing lateral view with cemented bipolar hemiarthroplasty with tension band wiring for Greater trochanter at 5 years post-op.

Fig 2.1- A -(magnified image)- Intra-operative image showing trans-trochanteric window with greater trochanter fragment retracted postero-supero-laterally and head visible through the window.

Figure 2.2-

A- Intra-operative image showing trans-trochanteric window with greater trochanter fragment retracted posterosupero-laterally and head visible trhough the window.

B and C- Intra-operative image showing head being extracted through with help of cork screw (head extractor).

D- Head extracted and acetabulum cleared and visualized.

E- Tension band wire passed through the lateral cortex of femur.

F- Cemented stem being inserted in the femoral canal .

Figure 3- Patient with cemented bipolar hemiarthroplasty in comminuted intertrochantertic fracture

A-Standing full weight bearing .

B-Sitting on chair comfortably.

C- Demonstrating Hip and knee flexion.

D- Demonstrating active straight leg raising.

\section{References}

[1]. P. Haentjens, P. P. Casteleyn, H. De Boek, F. Handelberg and P. Opdecam, "Treatment of Unstable Intertrochanteric and Subtrochanteric Fractures in Elderly. Primary Bipolar Arthroplasty Compared with Internal Fixation," Journal of Bone and Joint Surgery, Vol. 71, No. 8, 1989, pp. 1214- 1225.

[2]. Eiskjaer S, Otsgard SE, Jakobsen BW, Jensen J, Lucht U. Years of potential life lost after hip fracture among postmenopausal women. Acta Orthop Scand 1992. 63(3): 293-296.

[3]. Evans Em- The treatment of trochanteric fractures of femur, J Bone J Surg AM,1949; 31:190-203.

[4]. Marsh JL, SlongoTF, Agel J et al- Fracture and Dislocation Classification compendium, Orthopaedic trauma association Classification, database and outcome committee;J Orthop Trauma 2007, 21:S 1-133 .

[5]. Thomas AP- Dynamic Hip Screw that fails. Injury 1991; 22;45-46.

[6]. Kouvidis G,Katonis P,Kampas D, et al- Dual Lag screw Ceplalomedullary nail versus the classic sliding hip screw For stabilization of inter-trochanteric fractures- A prospective randomized Study.-Strategies Trauma Limb Reconstr. 2012 November; 7(3): 155-162.

[7]. Madsen JE,Naess L,Aune AK et al- Dynamic hip screw with trochanteric stabilization plate in treatment of unstable proximal femoral fractures. Acomparative study with Gamma nail and Dynamic compression screw; J orthop Trauma, 1998:12:241-8.

[8]. Goldhagen PR, O'Connor DR, Schwarze D, Schwartz E- A prospective comparative study of gamma nail and Dynamic hip screw. J ortho Trauma 1994;8;367-72.

[9]. Chan KC, Gill GS- Cemented Hemiarthriolasty for elderly patients with Inter-trochanteric fractures. Clin Orthop relat Res, 2000;371; 206-15.

[10]. Stern MB and goldstein TB. The use of leinbach prosthesis in intertrochantric fractures of hip. Clin Orthop 1977; $128 ; 325-9$. 
[11]. Kanis JA- Assesment of Fracture Risk and its application to screening for post-menopausal osteoporosis. Synopsis of WHO report. Osteoporosis Int, 1994,;4;368-81.

[12]. Kyle RF, Gystilo RB, Premer RF (1979) Analysis of six hundred and twenty one intertrochanteric hip fractures. A retrospectiveand prospective study. J Bone Joint Surg [Am] 61:219-221.

[13]. Jensen JS, Sonne-Holm S (1980) Critical analysis of Ender nailing in the treatment of trochanteric fractures. Acta Orthop Scand $51: 817-825$.

[14]. Stern MB, Angerman A- Comminuted Inter-trochanteric fractures treated with Leinbach Prosthesis, Clin Orthop Res Relat ;1987;218, 75-80.

[15]. Parker M, Johansen A. Clinical review. Hip fracture. Bmj. 2006; 333: 27-30.

[16]. Kannus P, Parkkari J, Sievänen H, heinonen A, Vuori I, Järvinen M.Epidemiology of hip fractures. Bone. 1996 Jan; $18(1$ Suppl):57s-63s.

[17]. C. Grimsrud, R. J. Monzon, J. Richman and M. D. Ries, "Cemented Hip Arthroplasty with a Novel Cerclage Ca-ble Technique for Unstable Intertrochanteric Hip Frac-tures,” The Journal of Arthroplasty, Vol. 20, No. 3, 2005, pp. 337-343.

[18]. C. Faldini, G. Grandi, M. Romagnoli, S. Pagkrati, V. Digennaro, O. Faldini and S. Giannini, "Surgical Treat- ment of Unstable Intertrochanteric Fractures by Bipolar Hip Replacement or Total Hip Replacement in Elderly Os- teoporotic Patients," Journal of Orthopaedics and Traumatology, Vol. 7, No. 3, 2006, pp. 117-121.

[19]. Kim WH, Han CH, Park JI, Kim JY - Failure of Inter-trochanteric fracture fixation with dynamic hip screw in relation to fracture stability and osteoporosis. Int Orthopaedics. 2001;25;360-2.

[20]. Rodop O, Kiral A, Kaplan H, Akmaz I- Primary Bipolar hemirosthesis for unstable inter-tro9chanteric fracture .Int Orthop 2002,26,233-7.

[21]. Grimsrud C, Monzon RJ, Richman J, Ries MD- Cemented Hip Arthroplasty with a novel cerclage cable techniquefor treatment of unstable Inter-trochanteric fracture. J Arthroplasty. 2005, 20;337-43.

[22]. Kayali C, Agus H,Ozluk S, Sanli C - Treatment of unstable inter-trochanteric fractures in elderly. Internal fixation vs Cone Hemiarthroplasty. J orthop Surg ( hong kong);2006;14;240-4.

[23]. Kesmezacar H, Ogut T, Bilgili MG, Gokay S, Tenekesioglu Y - Treatment of inter-trochanteric fractures in elderly patients; Internal fixation vs Hemiarthroplasty. Acta Orthop Traumatol Turc;2005, 39;287-94.

[24]. Kim WY, Han CH, park JI, Kim JY (2001) failure of intertrochanteric fracture fixation with a dynamic hip screw in relation to preoperative fracture stability and osteoporosis. Int Orthop 25:360-362.

[25]. Chapman MW, Bowman WE, Csongradi JJ et al. The use of enderspins in extracapsular fractures of the hip. J Bone Joint Surg 1981;65:14-28.

[26]. Zhang Q, Pang Q, Huang T, GE A, Tang T, Chen 1. The clinical effect of bipolar long-stem prosthetic replacement on the treatment of comminuted intertrochanteric fracture of hip in the elderly osteoporotic patients. Zhongguo Xiu Fu Chong Jian Wai Ke Za Zhi 2005 Mar; 19(3):198-200.

[27]. Haentjens P., G. Lamraski endoprosthetic replacement of unstable,comminuted intertrochanteric fracture of the femur in the elderly,osteoporotic patient: a review. Disability \& rehabilitation Jan 2005, Vol. 27, No. 18-19:1167-1180.

[28]. F. Geiger, M. Zimmermann-stenzel, C. Heisel, B. Lehner, W. Daecke trochanteric fractures in the elderly: the influence of primary hip arthroplasty on 1-year mortality Arch Orthop Trauma Surg (2007) 127:959-966.

[29]. Haidukewych, George J. MD; Israel, T. Andrew MD; Berry, Daniel J. MD- Long-Term Survivorship of Cemented Bipolar Hemiarthroplasty for Fracture of the Femoral Neck. Clin Orthop res Relat- Oct-2002- Vol 403, pp- 118-126.

[30]. Astvaldur J Arthursson, Ove Furnes, Birgitte Espehaug, Leif I Havelin, and Jon Arne Söreide-Prosthesis survival after total hip arthroplasty_does surgical approach matter? Analysis of 19,304 Charnley and 6,002 Exeter primary total hip arthroplasties reported to the Norwegian Arthroplasty Register. Acta Orthopaedica 2007; 78 (6): 719-729.

[31]. Rodop O, Kiral A, Kaplan H, Akmaz I (2002) Primary bipolar hemiprosthesis for unstable intertrochanteric fractures. Int Orthop 26:233-237.

[32]. Kwon MS, Kuskowski M, Mulhall KJ et al - Does surgical approach affect Total hip arthroplasty dislocation rates?- A metaanalysis.Clin Orthop Res Relat- June 2006; Number 447, pp. 34-38.

[33]. Sancheti KH, Sancheti PK, Shyam AK et al- Primary Hemiarthroplasty for unstable inter-trochanteric fractures in osteoporotic elderly patients- A retrospective case series.Indian J Ortho. Oct 2010,VO1 44, Issue 4;pp 428-34.

[34]. Ahmed Elmorsy, Mahmoud Saied, Adel Awad Allah, Mahmoud Zaied, Mahmoud Hafez- Primary Bipolar Arthroplasty in Unstable Intertrochanteric Fractures in Elderly; Open Journal of Orthopedics, 2012, 2, 13-17.

[35]. Parker MJ, Handol HH- Replacement arthroplasty vs Internal Fixation For extracapsular hip fractures. Cochrane Database Syst Rev;2006;2; CD 000086.

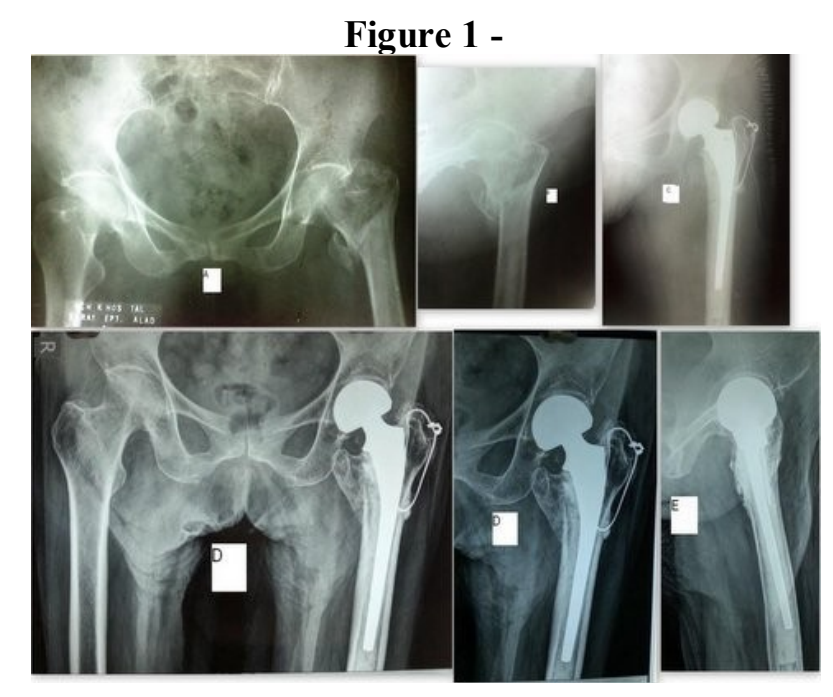


Figure 2.1-

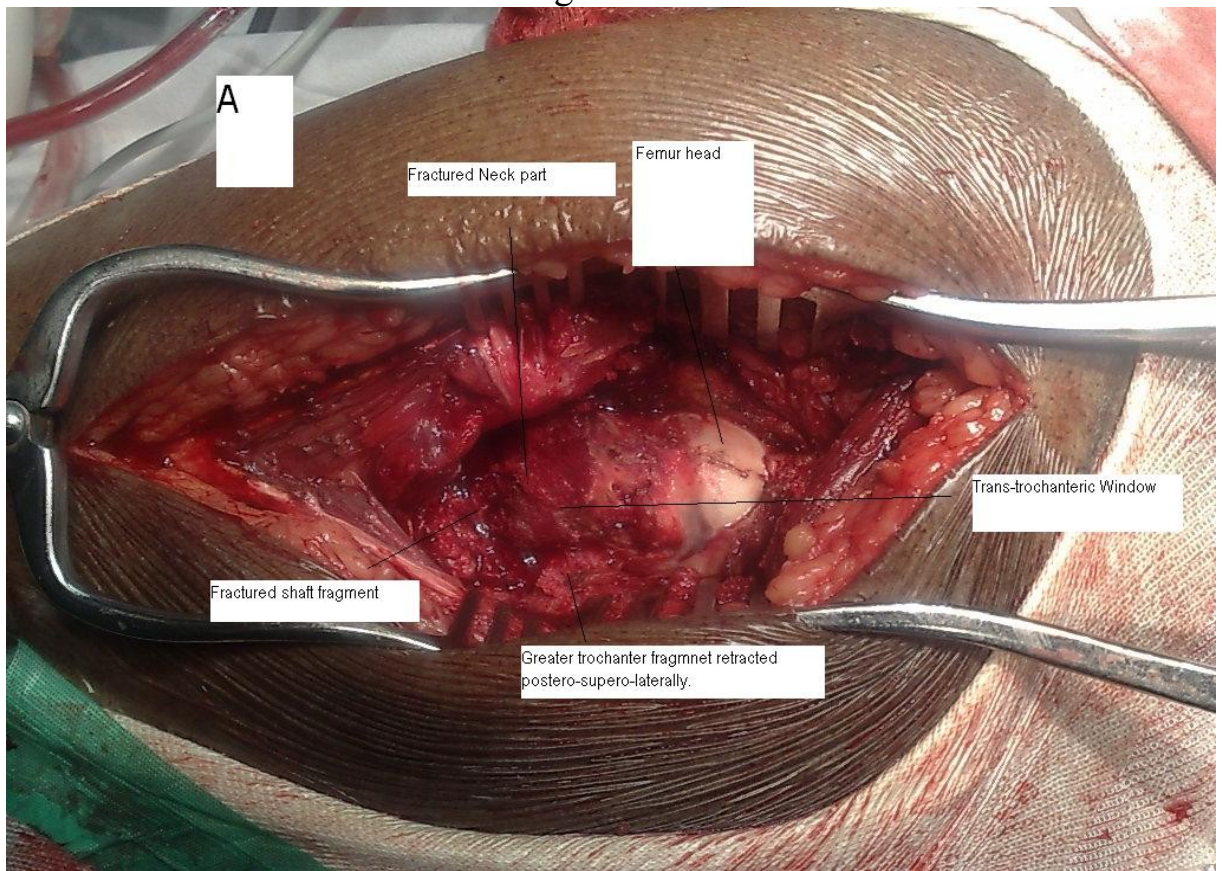

Figure $2.2-$

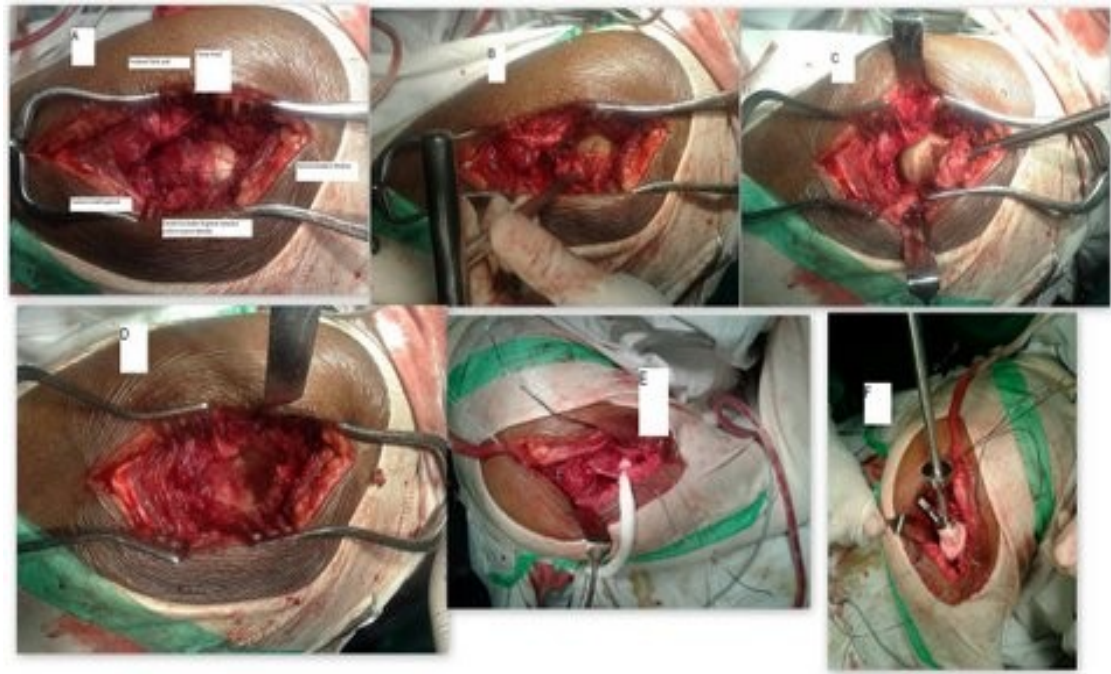

Figure 3-

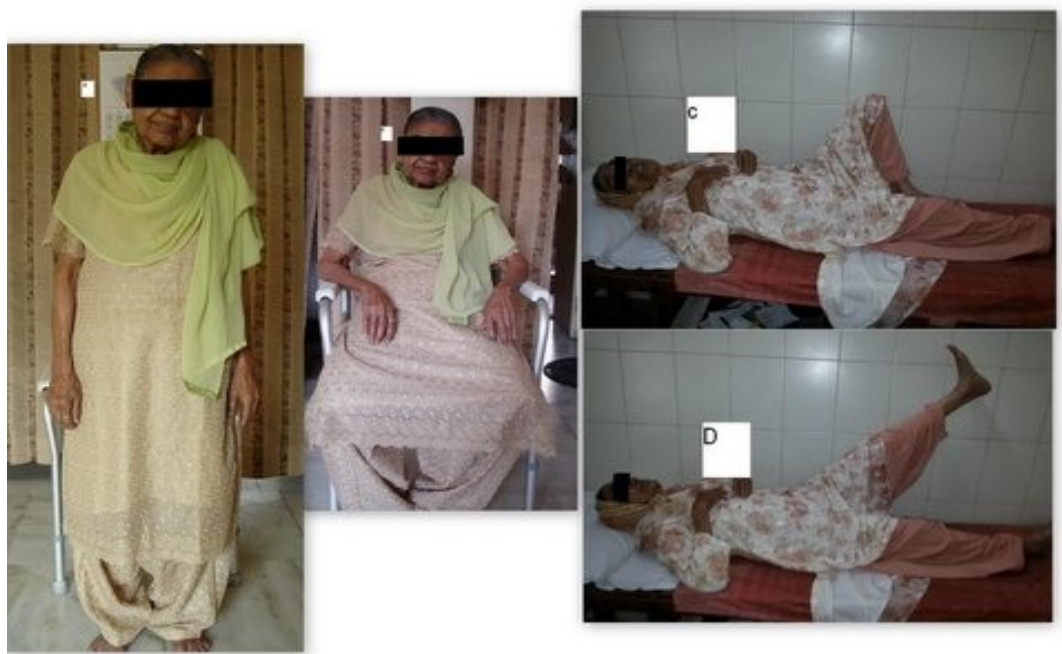

